\title{
Study on Vibration Reduction Due to Pile- Raft Foundation for High-Tech Lab Based on Frequency Sweep Test
}

\author{
Yan XIA ${ }^{1}$ \\ China Electronics Engineering Design Institute CO., LTD, Beijing 100142, China
}

\begin{abstract}
Evaluation of the vibration reduction of piled-slab is of great significance for the layout of process and power equipment in high-tech facilities. In-situ measurement was performed to study the vibration reduction of the piled-slab of a high-tech lab. Slab vibrations with frequencies of $10 \mathrm{~Hz}$ to $60 \mathrm{~Hz}$ with steps $5 \mathrm{~Hz}$ were induced by an electromagnetic vibration exciter. INV3062U data acquisition device and 941B sensor were used to measure the velocities in the vertical direction at six measurement locations on the slab surface. For single frequency, the measurement results showed that the peak values of the slab vibration velocities generally decayed nonlinearly as the distance increased, however, the attenuations of $25 \mathrm{~Hz}, 35 \mathrm{~Hz}, 40 \mathrm{~Hz}, 50 \mathrm{~Hz}$ and $60 \mathrm{~Hz}$ slab vibrations were not monotonically.
\end{abstract}

Keywords. Vibration reduction, piled-slab, frequency sweep test

\section{Introduction}

Environmental vibrations induced by power equipment can disturb the operation of vibration-sensitive equipment in the high-tech facilities [1, 2]. Among the power equipment of interest, internal power equipment is one of the major malfunction factors for precision instrument and equipment in the same high-tech facilities because the internal power equipment and vibration-sensitive equipment are quite close [3]. In order to achieve the normal operation of vibration-sensitive equipment, suitable measures should be adopted to reduce the vibrations caused by power equipment to allowable levels [4-6]. Thickened foundation slab and pile-raft foundation have been proved to be reliable vibration isolation measures for high-tech facilities.

Scholars and engineers have performed many studies on the vibration reduction of thickened slab and piled-slab based on test and numerical simulation methods. Simulation analysis on the vibration reduction efficiency of thin flexural plates with different thicknesses that were located on an elastic half-space was carried out by Auersch [7]. The results showed that the dominant parameter in reducing the slab vibrations was slab thickness. Gao et al. [8] conducted in situ measurement and numerical simulation studies on a one story high-tech electronics workshop with a pileraft foundation to reveal the vibration reduction ability of the pile-raft foundation. It was showed that the pile-raft foundation had reduction effect on the horizontal vibrations in the frequency under $60 \mathrm{~Hz}$ and amplification effect on the vertical vibrations in the

${ }^{1}$ Corresponding Author, Yan XIA, China Electronics Engineering Design Institute CO., LTD, Beijing 100142, China; Email: xiayan@ceedi.cn. 
frequency over $30 \mathrm{~Hz}$. Based on test and an analytical model, Sanayei et al. [9] investigated the effect of slab thickness on its vibration reduction. They concluded that thickening the foundation slab can be used as a reliable measure in controlling environmental vibrations induced by external vibration sources. Amick et al. [10] carried out a series of vibration measurements to study the reduction effect of different slab types on environmental vibrations. For the vertical vibrations caused by external excitation sources, the piled-slab foundation showed better reduction effect than the slab-on-ground foundation.

Compared with analytical and numerical methods, the field vibration test is often used to obtain comprehensive information on the vibration reduction of piled-slab. However, field measurement and analysis on the vibration reduction of thickened slab and piled-slab based on in situ vibration frequency sweep test are scarce in literature. This paper focuses on the evaluation of vibration reduction of the pile-raft foundation of a high-tech lab. The evaluation is implemented by conducting in situ vibration measurement. This study is to provide a series of vibration data that researchers and engineers can use for further investigation and for the design of similar project. First, the experimental program of the in situ vibration frequency sweep test is briefly introduced. Then, the measurement results are analyzed and discussed.

\section{Experimental Program}

\subsection{Project and Construction Site Overview}

The high-tech lab that is to be studied is a one story reinforced concrete frame structure, with an area of $12280 \mathrm{~m}^{2}$. As shown in figure 1, the foundation form used for the hightech lab is pile-raft foundation. The raft slab is $146 \mathrm{~m} \times 83 \mathrm{~m} \times 0.5 \mathrm{~m}(\mathrm{~L} \times \mathrm{W} \times \mathrm{T})$. The raft slab is directly used as the first floor of the high-tech lab. The pile type is bored pile, with a diameter of $800 \mathrm{~mm}$ and a length of $15 \mathrm{~m}$.

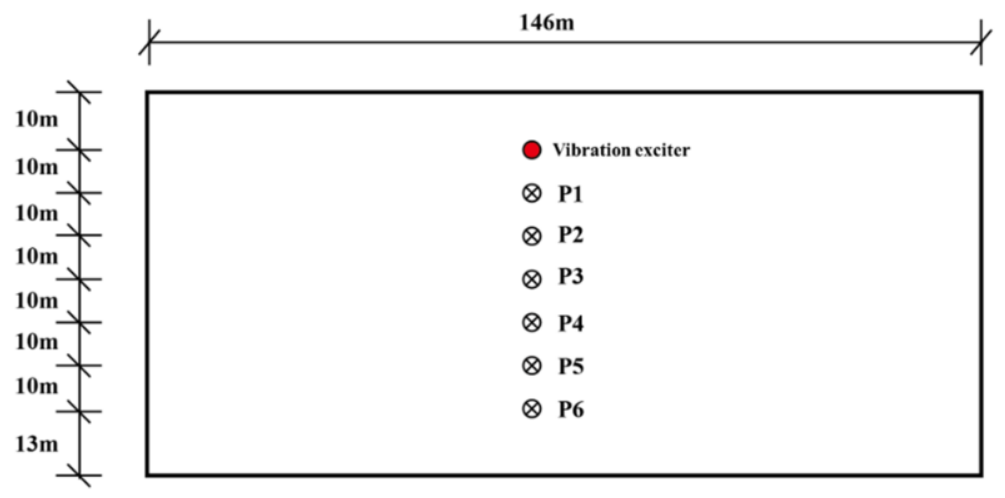

Figure 1. The high-tech lab.

The construction site locates in Chengdu, China. The geotechnical and geophysical investigation show that the site is layered soil in the depth of $30 \mathrm{~m}$. Table 1 gives the soil parameters of the construction site. 
Table 1. Soil parameters of the site.

\begin{tabular}{lllll}
\hline Layer & Thickness $(\mathbf{m})$ & Density $\left(\mathbf{k g} / \mathbf{m}^{\mathbf{3}}\right)$ & Shear wave velocity $\mathbf{( m / s )}$ & Poisson Ratio \\
\hline Artificial fill & $2.4 \sim 6.3$ & 1800 & 138 & 0.37 \\
Silt clay & $1.1 \sim 1.6$ & 2000 & 98 & 0.42 \\
Silt clay & $0.7 \sim 2.6$ & 1900 & 219 & 0.38 \\
Gravel & $0.5 \sim 1.8$ & 2150 & 331 & 0.30 \\
Sandy mudstone & $0.5 \sim 2.3$ & 2100 & 229 & 0.33 \\
Sandy mudstone & $1.4 \sim 3.7$ & 2300 & 271 & 0.29 \\
Sandy mudstone & ------ & 2400 & 766 & 0.23 \\
\hline
\end{tabular}

\subsection{Dynamic Tests}

In the in-situ test, harmonic vibrations at frequencies varying from $10 \mathrm{~Hz}$ to $60 \mathrm{~Hz}$ with steps of $5 \mathrm{~Hz}$ were generated by an electromagnetic vibration excitation system. The time history of each harmonic vibration lasts $20 \mathrm{~s}$. The excitation system mainly consists of four parts: a signal generator, a power control cabinet, an electromagnetic exciter, and an air-cooled machine, as shown in figure 2.

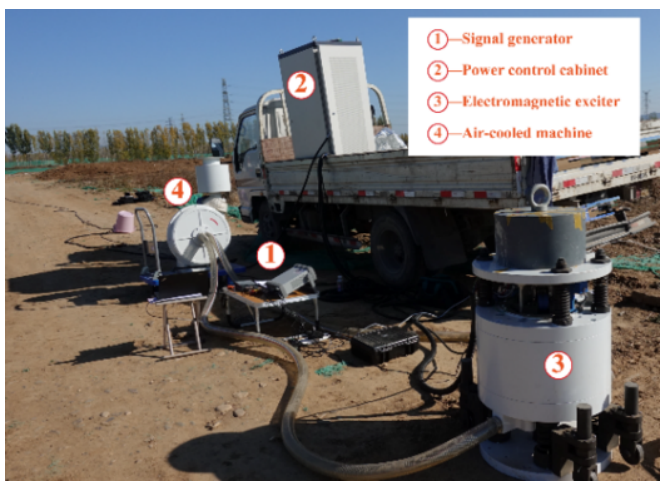

Figure 2. Illustration of the electromagnetic vibration excitation system.

The dynamic forces generated by the electromagnetic excitation were directly applied on the slab surface, then vibrations were generated and propagated. Low frequency, 1 component, 941B sensor was used to measure the vertical velocities of the slab vibrations at six locations with different distances from the vibration source: $10 \mathrm{~m}$, $20 \mathrm{~m}, 30 \mathrm{~m}, 40 \mathrm{~m}, 50 \mathrm{~m}$ and $60 \mathrm{~m}$, see figure 1 .

\section{Results and Discussion}

\subsection{Peak Velocity}

The peak vibration velocities of the slab at the 6 measurement points obtained by equation (1) were used to evaluate the vibration levels.

$$
\mathrm{V}_{\mathrm{p}}(\omega)=\max |v(\omega, t)|
$$


where $v(\omega, t)$ is the vibration velocity time history in the vertical direction at frequency $\omega$.

The attenuation law of single frequency vibrations a long distance is plotted in figure 3.

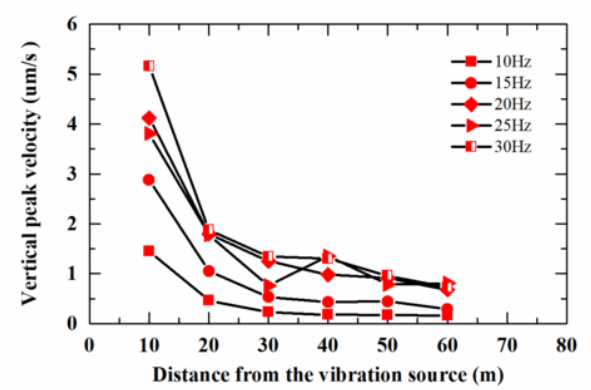

(a) $10 \mathrm{~Hz}$ to $30 \mathrm{~Hz}$ with steps of $5 \mathrm{~Hz}$

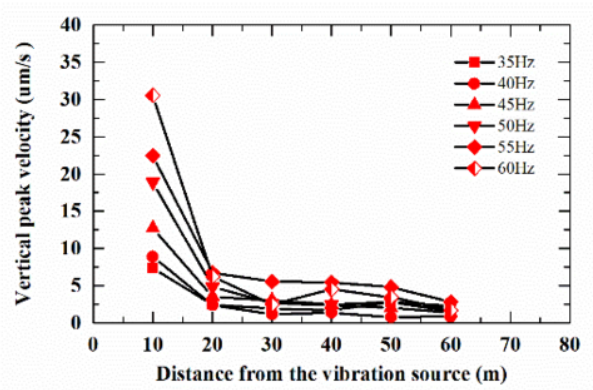

(b) $35 \mathrm{~Hz}$ to $60 \mathrm{~Hz}$ with steps of $5 \mathrm{~Hz}$

Figure 3. Vertical peak velocity plotted against distance.

Because of the geometric damping and material damping of foundation soil and slab material, the slab vibrations of single frequency generally decay nonlinearly with distance from the first measurement point, $\mathrm{P}_{1}$. The vertical peak velocities of slab vibrations at different frequencies were unequal at the first measurement point, $\mathrm{P}_{1}$. This was because the dynamic forces with different frequencies generated by the electromagnetic vibration excitation system were different.

Moreover, the attenuations of $25 \mathrm{~Hz}, 35 \mathrm{~Hz}, 40 \mathrm{~Hz}, 50 \mathrm{~Hz}$ and $60 \mathrm{~Hz}$ slab vibrations were not monotonic. This was because the vibration responses at the slab surface were the superposition of the propagated vibrations along the slab surface and the reflected vibrations from the soil interfaces and soil-slab interface. Vibrations generated by the electromagnetic vibration exciter propagated simultaneously along the slab surface and the slab depth and soil depth. When the vibrations propagated along the depth to the soilslab interface and soil interfaces, part of the vibrations was reflected back to the slab surface. The effect of vibration interference resulted in the non-monotonicity of the attenuations of $25 \mathrm{~Hz}, 35 \mathrm{~Hz}, 40 \mathrm{~Hz}, 50 \mathrm{~Hz}$ and $60 \mathrm{~Hz}$ slab vibrations, see figure 3.

\subsection{Vibration Transmissibility}

In order to quantify the attenuation characteristics of the slab vibrations for different vibration frequencies, the transmissibility is employed to evaluate the attenuation degree of the vibrations between two measurement locations. The transmissibility is defined as:

$$
\mathrm{T}_{i j}(\omega)=\frac{X_{i}(\omega)}{X_{j}(\omega)}
$$

where $\mathrm{T}_{i j}(\omega)$ is the transmissibility of the vibration levels of measurement point $\mathrm{P}_{i}$ with respect to that of measurement point $\mathrm{P}_{j} \cdot X_{i}(\omega)$ and $X_{j}(\omega)$ are the FFT coefficients of the vibration level time histories at the two measurement points $\mathrm{P}_{i}$ and $\mathrm{P}_{j}$, respectively. 
For harmonic signals, here the vertical velocity time histories, the FFT coefficient of a vertical velocity time history equals to the corresponding peak velocity. Therefore, the transmissibility defined in terms of the FFT coefficient $X(\omega)$ can be written in terms of the peak velocity as:

$$
\mathrm{T}_{i j}(\omega)=\frac{\mathrm{V}_{\mathrm{pi}}(\omega)}{\mathrm{V}_{\mathrm{pj}}(\omega)}
$$

In order to analyse the relationship between the peak velocity transmissibility and the distance from the excitation source, the peak velocity transmissibility $\mathrm{T}_{i 1}(i=2,3,4$, 5,6 ) between the $20 \mathrm{~m}, 30 \mathrm{~m}, 40 \mathrm{~m}, 50 \mathrm{~m}, 60 \mathrm{~m}$ measurement points and the $10 \mathrm{~m}$ measurement point are calculated and shown in table 2 .

As noted in table 2 , the peak velocity transmissibility $\mathrm{T}_{i 1}(i=2,3,4,5,6)$ of the slab vibrations in general decreases as the distance from the dynamic excitation increases. For instance, the peak velocity transmissibility $T_{21}$ of $10 \mathrm{~Hz}$ vibrations is $31.72 \%$ indicating that the peak velocity at $20 \mathrm{~m}$ measurement point decreases (100-31.72) $\%=68.28 \%$ compared with the $10 \mathrm{~m}$ measurement point. As the distance increases to 30 $\mathrm{m}, 40 \mathrm{~m}, 50 \mathrm{~m}$ and $60 \mathrm{~m}$, the peak velocity transmissibility decreases to $15.86 \%, 12.41 \%$, $11.72 \%$ and $11.03 \%$, which means that the peak velocity at $30 \mathrm{~m}, 40 \mathrm{~m}, 50 \mathrm{~m}$ and $60 \mathrm{~m}$ measurement points decrease $84.14 \%, 87.59 \%, 88.28 \%$ and $88.97 \%$ compared with the $10 \mathrm{~m}$ measurement point, respectively.

It is also clearly in table 2 that the decreases in the peak velocity transmissibility $\mathrm{T}_{i 1}$ $(i=2,3,4,5,6)$ for $25 \mathrm{~Hz}, 35 \mathrm{~Hz}, 40 \mathrm{~Hz}, 50 \mathrm{~Hz}$ and $60 \mathrm{~Hz}$ vibrations are oscillatory, which is in consistent with the attenuation characteristics of the peak velocity shown in figure 3. For instance, the peak velocity transmissibility at $50 \mathrm{~m}$ measurement point for $15 \mathrm{~Hz}$ vibration is $15.28 \%$, which is larger than the $14.93 \%$ at $40 \mathrm{~m}$ measurement point. This means the peak velocity at $50 \mathrm{~m}$ measurement point increases $15.28 \% / 14.93 \%=1.02 \%$ compared with the $40 \mathrm{~m}$ measurement point.

Table 2. Transmissibility relative to the $10 \mathrm{~m}$ measurement point (\%).

\begin{tabular}{|c|c|c|c|c|c|}
\hline Freq. (Hz) & $\begin{array}{l}T_{12}\left(P_{1}-P_{2}\right) \\
(10 \mathrm{~m}-20 \mathrm{~m})\end{array}$ & $\begin{array}{l}T_{13}\left(P_{1}-P_{3}\right) \\
(10 \mathrm{~m}-30 \mathrm{~m})\end{array}$ & $\begin{array}{l}T_{14}\left(P_{1}-P_{4}\right) \\
(10 \mathrm{~m}-40 \mathrm{~m})\end{array}$ & $\begin{array}{l}T_{15}\left(P_{1}-P_{5}\right) \\
(10 \mathrm{~m}-50 \mathrm{~m})\end{array}$ & $\begin{array}{l}T_{16}\left(P_{1}-P_{6}\right) \\
(10 \mathrm{~m}-60 \mathrm{~m})\end{array}$ \\
\hline 10 & 31.72 & 15.86 & 12.41 & 11.72 & 11.03 \\
\hline 15 & 36.46 & 18.4 & 14.93 & 15.28 & 10.07 \\
\hline 20 & 43.69 & 30.34 & 23.79 & 22.09 & 16.5 \\
\hline 25 & 46.72 & 19.95 & 35.43 & 20.47 & 21.26 \\
\hline 30 & 36.43 & 25.97 & 25.19 & 18.6 & 13.95 \\
\hline 35 & 33.06 & 26.26 & 23.54 & 38.23 & 21.22 \\
\hline 40 & 26.97 & 13.15 & 15.62 & 8.76 & 9.33 \\
\hline 45 & 27.74 & 23.96 & 19.23 & 16 & 10.72 \\
\hline 50 & 25.72 & 13.94 & 12.73 & 14.95 & 12.09 \\
\hline 55 & 30.08 & 24.69 & 24.29 & 21.43 & 12.52 \\
\hline 60 & 20.35 & 8.08 & 14.73 & 11.26 & 5.56 \\
\hline
\end{tabular}

The peak velocity transmissibility $\mathrm{T}_{i 1}(i=2,3,4,5,6)$ of the slab vibrations describes the transmit of the absolute vibration level from the first measurement point $\mathrm{P}_{1}$ to the measurement point $\mathrm{P}_{i}$, which represents the absolute ability of soil-pile-slab system to transmit and decay the vibrations. In order to analyse relative ability of soil- 
pile-slab to decay the vibrations, the peak velocity transmissibility per meter $\mathrm{T}_{i i+1}^{\prime}(i=1$, $2,3,4,5)$ between the two adjacent measurement points are calculated and shown in table 3 .

Table 3. Transmissibility between two adjacent measurement points (\%).

\begin{tabular}{|c|c|c|c|c|c|}
\hline $\begin{array}{l}\text { Freq. } \\
\text { (Hz) }\end{array}$ & $\begin{array}{l}T_{12}\left(P_{1}-P_{2}\right) \\
(10 \mathrm{~m}-20 \mathrm{~m})\end{array}$ & $\begin{array}{l}\mathrm{T}_{23}\left(\mathrm{P}_{2}-\mathrm{P}_{3}\right) \\
(20 \mathrm{~m}-30 \mathrm{~m})\end{array}$ & $\begin{array}{l}T_{34}\left(P_{3}-P_{4}\right) \\
(30 \mathrm{~m}-40 \mathrm{~m})\end{array}$ & $\begin{array}{l}T_{45}\left(P_{4}-P_{5}\right) \\
(40 \mathrm{~m}-50 \mathrm{~m})\end{array}$ & $\begin{array}{l}T_{56}\left(P_{5}-P_{6}\right) \\
(50 \mathrm{~m}-60 \mathrm{~m})\end{array}$ \\
\hline 10 & 31.72 & 50 & 78.26 & 94.44 & 94.12 \\
\hline 15 & 36.46 & 50.48 & 81.13 & 102.33 & 65.91 \\
\hline 20 & 43.69 & 69.44 & 78.4 & 92.86 & 74.73 \\
\hline 25 & 46.72 & 42.7 & 177.63 & 57.78 & 103.85 \\
\hline 30 & 36.43 & 71.28 & 97.01 & 73.85 & 75 \\
\hline 35 & 33.06 & 79.42 & 89.64 & 162.43 & 55.52 \\
\hline 40 & 26.97 & 48.75 & 118.8 & 56.12 & 106.41 \\
\hline 45 & 27.74 & 86.36 & 80.26 & 83.2 & 67 \\
\hline 50 & 25.72 & 54.23 & 91.25 & 117.5 & 80.85 \\
\hline 55 & 30.08 & 82.07 & 98.38 & 88.26 & 58.42 \\
\hline 60 & 20.35 & 39.71 & 182.19 & 76.44 & 49.42 \\
\hline
\end{tabular}

The peak velocity transmissibility $\mathrm{T}_{i i+1}^{\prime}(i=1,2,3,4,5)$ represents the relative value of the peak velocities of the slab vibrations between two adjacent measurement points $\mathrm{P}_{i+1}$ and $\mathrm{P}_{i}$. Therefore, in table 3, the closer to $100 \%$ the transmissibility $\mathrm{T}_{i i+1}^{\prime}$, the closer the two peak velocities. For instance, the transmissibility $\mathrm{T}_{34}^{\prime}=78.26 \%$ of $10 \mathrm{~Hz}$ vibrations is closer to $100 \%$ compared with $\mathrm{T}_{12}^{\prime}=31.72 \%$, explaining the fact that the two peak velocities $0.23 \mathrm{um} / \mathrm{s}$ and $0.18 \mathrm{um} / \mathrm{s}$ at measurement points $\mathrm{P}_{3}$ and $\mathrm{P}_{4}$ are closer than the two peak velocities $1.45 \mathrm{um} / \mathrm{s}$ and $0.46 \mathrm{um} / \mathrm{s}$ at measurement points $\mathrm{P}_{1}$ and $\mathrm{P}_{2}$.

Especially, in table 3, a transmissibility $\mathrm{T}_{i i+1}^{\prime}$ that is greater than $100 \%$ indicates that the peak velocity of slab vibrations at measurement point $\mathrm{P}_{i+1}$ is larger than that measurement point $\mathbf{P}_{i}$. For instance, the transmissibility $\mathrm{T}_{45}^{\prime}$ of $15 \mathrm{~Hz}$ vibrations is $102.33 \%$, explaining that the peak velocity at $50 \mathrm{~m}$ measurement point increases $15.28 \% / 14.93 \%=1.02 \%$ compared with the $40 \mathrm{~m}$ measurement point.

\section{Conclusions}

The attenuation law of slab vibrations was studied based on vibration frequency sweep measurement. The frequency range of the slab vibrations was $10 \mathrm{~Hz}$ to $60 \mathrm{~Hz}$. The frequency interval of the frequency sweep measurement was $5 \mathrm{~Hz}$. It can be concluded that:

(1) The peak velocity of single frequency slab vibrations generally decayed nonlinearly and monotonically with distance from the first measurement point.

(2) The $25 \mathrm{~Hz}, 35 \mathrm{~Hz}, 40 \mathrm{~Hz}, 50 \mathrm{~Hz}$ and $60 \mathrm{~Hz}$ slab vibrations decayed nonmonotonically because the interference effect between the propagated vibrations along the slab surface and the reflected vibrations. 
(3) Compared with the vibration velocities far away from the vibration source, the peak velocities of slab vibrations attenuated more rapidly in the zone nearby the vibration source.

\section{References}

[1] Brownjohn J 2005 Vibration Control of Sensitive Manufacturing Facilities (Actes Des Journées Scientifiques Du Lcpc).

[2] Kim H S and Kang J W 2017 Smart platform for microvibration control of high-tech industry facilities International Journal of Steel Structures 17 155-64.

[3] Ulgen D and Toygar O 2015 Screening effectiveness of open and in-filled wave barriers: A full-scale experimental study Construction and Building Materials 86 12-20.

[4] Guo A, Xu Y and Hui L 2005 Road vehicle-induced vibration control of microelectronics facilities Earthquake Engineering and Engineering Vibration 4 139-51.

[5] Gordon C G 1992 Generic Criteria for Vibration-Sensitive Equipment (San Jose - DL Tentative) pp 7185.

[6] Amick H and Gendreau M 2000 Construction vibrations and their impact on vibration-sensitive facilities Construction Congress VI.

[7] Auersch L 2013 Response to harmonic wave excitation of finite or infinite elastic plates on a homogeneous or layered half-space Computers \& Geotechnics 51 50-9.

[8] Gao G, Chen J, Yang J and Meng Y 2017 Field measurement and FE prediction of vibration reduction due to pile-raft foundation for high-tech workshop Soil Dynamics and Earthquake Engineering 101 2648 .

[9] Sanayei M, Anish K P, Moore J A and Brett C R 2014 Measurement and prediction of train-induced vibrations in a full-scale building Engineering Structures 77 119-28.

[10] Amick H, Wongprasert N, Montgomery J, Haswell P and Lynch D 2005 An experimental study of vibration attenuation performance of several on-grade slab configurations SPIE Proceedings (Bellingham, WA). 